\title{
Successful pregnancy outcome of a patient with ulcerative colitis and antiphospholipid antibody syndrome with recurrent pregnancy loss
}

\author{
Kodandapani $\mathrm{S}^{*}$ \\ Department of Obstetrics and Gynecology, Kasturba Medical College, Manipal University, Manipal, India
}

\section{Introduction}

Ulcerative colitis in pregnancy is usually uneventful and have been reported as successful pregnancy outcomes. Only one case is reported with coincidental antiphospholipid syndrome

Ulcerative Colitis (UC) is an inflammatory bowel disease presenting as recurrent abdominal pain and bloody diarrhoea. We present a case of successful pregnancy outcome with ulcerative colitis and antiphospholipid antibody syndrome.

\section{Case report}

A 27-year-old gravida 4 abortion 2 intrauterine death 1 presented to medicine department with recurrent bloody diarrhea and pain abdomen for 6 months. Colonic biopsy diagnosed ulcerative colitis. Patient was referred to us with history of previous recurrent abortions and short period of amenorrhea. She had two first trimester (810 weeks) spontaneous abortions and one previous intrauterine fetal death with eclampsia and placental abruption. As history was suggestive of Antiphopholipid antibody syndrome, APLA panel was advised. APTT was prolonged, ACA was positive and dRVVT was strongly positive. Thus, APLA syndrome was diagnosed. Transvaginal sonography confirmed early intrauterine pregnancy with good cardiac activity. She was started on aspirin $75 \mathrm{mg}$ per day and low molecular weight heparin 5000 IU per day. She was also on Mesalazaine 750 $\mathrm{mg}$ per day and prednisolone $10 \mathrm{mg}$ per day for the treatment of ulcerative colitis. Pregnancy was uneventful. Frequent antenatal checkups included monitoring of fetal growth, coagulation profile and $\mathrm{BP}$ monitoring. Mild IUGR was noted with good amniotic fluid and good diastolic flow in umbilical artery Doppler. She had one episode of acute abdominal pain with diarrhoea and was managed conservatively. At 36 weeks, patient presented with high BP160/110 mmHg and imminent symptoms of headache and epigastric pain. Patient was taken up emergency caesarean delivery. She had taken LMWH 6 hours earlier and hence regional anaesthesia was considered. She delivered baby boy with birth weight of $2 \mathrm{KG}$. She received LMWH for one week after delivery and immediate postpartum period was uneventful.

\section{Discussion}

It is noteworthy in this case that patient had two dreadful diseases and could go home with a baby due to careful antenatal care and timely delivery.

Both diseases deserve a lengthy discussion here. Ulcerative colitis is a chronic inflammatory bowel disease and its management during pregnancy is a challenge. Disease may aggravate during pregnancy certain times and there are studies wherein patients had to undergo bowel resection and anastomosis [1]. Our patient had few episodes of bloody diarrhoea and pain abdomen but did not aggravate further. During acute episodes, prednisolone doses were adjusted and managed conservatively. Mesalsazine is the standard treatment for UC. There are studies with oral and rectal preparations. Our patient received oral preparation and there were no untoward incidents. Since drug is category $B$, there were no congenital malformations in fetus $[2,3]$. A large prospective European study with UC showed $67 \%$ remission with active disease during pregnancy [4]. A Danish study has reported $40.3 \%$ relapses during pregnancy in UC as compared to $13.6 \%$ in the 6 months prior to pregnancy. Exacerbations of disease, particularly in the first trimester of pregnancy are often due to discontinuation of maintenance therapy [5,6]. Whether disease flares are more likely to occur in the postpartum period remains controversial, but pregnancy seems to have a beneficial effect on the disease course of IBD. A small prospective study reported a decrease in relapse rate in UC patients four years after pregnancy, in comparison with the 3 years before pregnancy. Postpartum flare seen in few patients is due to discontinuation of drugs rather than any other disease problems $[7,8]$. Prednisolone upto $15 \mathrm{mg} /$ day is safe throughout pregnancy. Although oral clefts are reported, they are not significant [9]. However, they are inactivated once they cross placenta by $11 \beta$ hydroxyl dehydrogenase. Hence either betamethasone or dexamethasone is administered to treat fetus [10]. Our patient received prednisolone $10 \mathrm{mg}$ per day throughout pregnancy. She did not have any adverse effects and also received Betamethasone for lung maturity at 28 weeks.

Our patient also had antiphospholipid antibody syndrome diagnosed by positive ACA, positive dRVVT and clinical criteria. Hence, she was on aspirin and low molecular weight heparin therapy.

Many studies insist two lab values at 6 weeks' interval positivity as significant criteria, but there are also studies who are content with one. Here we have done once and took timely decision of starting heparin therapy. Sudden progression of the disease is the characteristic feature in APLA syndrome as we observed in our case of sudden imminent

Correspondence to: Sreelakshmi Kodandapani, Department of Obstetrics and Gynecology, Kasturba Medical College, Manipal University, Manipal, India; Tel: 0820292 2367; E-mail: laxmivinayaka@gmail.com

Received: December 13, 2016; Accepted: January 05, 2017; Published: January 09, 2017 
symptoms within a week, hence careful monitoring is advocated $[11,12]$.

Hence, we conclude from this case that careful monitoring and frequent antenatal care for high risk pregnancy is the key to success.

\section{References}

1. Aytac E, OzunerE, Isik O, Gorgun E, Remzi FH (2015) Surgical management of patients withulcerative colitis during pregnancy: Maternal and fetal outcomes. J Crohns Colitis 9: 82-85. [Crossref]

2. Probert SJC, Dignass AU, Lindgren S, Pool OM, Marteau P (2014) Combined oral and rectal mesalazine for thetreatment of mild-to-moderately active ulcerative colitis: Rapid symptom resolution and improvements in quality of life. $J$ Crohns Colitis 8: 200-207. [Crossref]

3. Dignass A, Lindsay JO, Sturm A, Windsor A, Colombel J-F, et al. (2012) Second European evidence-based Consensus on the diagnosis and management of ulcerative colitis: current management. J Crohns Colitis 6: 991-1030. [Crossref]

4. Bortoli A, Pedersen N, Duricova D, D'Inca R, Gionchetti P, et al. (2011) Pregnancy outcome in inflammatory bowel disease: prospective European case-control ECCOEpiCom study. Aliment Pharmacol Ther 34: 724-734. [Crossref]

5. Julsgaard M, Nørgaard M, Hvas CL, Buck D, Christensen LA (2010) Self-reported adherence to medical treatment prior to and during pregnancy among women with ulcerative colitis. Inflamm Bowel Dis 17: 1-8. [Crossref]

6. Ferrero S, Ragni N (2004) Inflammatory bowel disease: management issues during pregnancy. Arch Gynecol Obstet 270: 79-85. [Crossref]

7. Kane S, Lemieux N (2005) The role of breastfeeding in postpartum disease activity in women with inflammatory bowel disease. Am J Gastroenterol 100: 102-105. [Crossref]

8. Moffatt DC, Ilnyckyj A, Bernstein CN (2009) A population-based study of breastfeeding in inflammatory bowel disease: initiation, duration, and effect on disease in the postpartum period. Am J Gastroenterol 104: 2517-2523. [Crossref]

9. Ogueh O, Johnson MR (2000) The metabolic effect of antenatal corticosteroid therapy Hum Reprod Update 6: 169-176. [Crossref]

10. Park-Wyllie L, Mazzotta P, Pastuszak A, Moretti ME, Beique L, et al. (2000) Birth defects after maternal exposure to corticosteroids: prospective cohort study and metaanalysis of Epidemiological studies. Teratology 62: 385-392. [Crossref]

11. Kutteh WH (1996) Antiphospholipid antibody-associated recurrent pregnancyloss treatment with heparin and low-dose aspirin is superior tolow-dose aspirin alone. Am J Obstet Gynecol 174: 1584-1589. [Crossref]

12. Empson M, Lassere M, Craig JC, Scott JR (2002) Recurrent pregnancy loss with antiphospholipid antibody: a systematic review of therapeutic trials. Obstet Gynecol 99: 1335-1344. [Crossref]

Copyright: (C2017 Kodandapani S. This is an open-access article distributed under the terms of the Creative Commons Attribution License, which permits unrestricted use, distribution, and reproduction in any medium, provided the original author and source are credited. 